\title{
Measurements of solids concentration and axial solids velocity in gas-solid two-phase flows
}

\author{
J.J. Nieuwland, R. Meijer, J.A.M. Kuipers, W.P.M. van Swaaij \\ Twente University. PO Box 217, 7500 AE Enschede, Netherlands \\ Received 14 February 1995; revised 26 Scplember 1995
}

\begin{abstract}
Several techniques reported in the literature for measuring solids concentration and solids velocity in (dense) gas-solid two-phase flow have been briefly reviewed. An optical measuring system, based on detection of light reflected by the suspended particles, has been developed to measure local solids concentration and local axial solids velocity in dense gas-solid two phase flows. This system has been applied to study hydrodynamics of a cold-flow circuiating fluidized bed unit operated in the dense flow regime $\left(u^{\mathrm{o}}: 7.5-15 \mathrm{~m} \mathrm{~s}^{-1}\right.$ and $G_{\mathrm{s}} \neq 100-400 \mathrm{~kg} \mathrm{~m}$ $\mathrm{s}^{-1}$ ). With increasing solids mass flux, at constant superficial gas velocity, lateral solids segregation became more pronounced (i.e. extent of development of core--annulus structure) while the radial profiles of axial solids velocity hardly changed. A decreise in superficial gas velocity, al constant solids mass flux, also augmented the lateral solids segregation. The axial solids velocity decreased over the entire tube radius, although the shape of the profiles showed no strong dependence with respect to the superficial gas velocity. Average solids mass fluxes calculated from the measured local values of solids concentration and solids velocity exceeded the imposed solids mass flux, a finding which could be explained by the downflow observed visually of solid particles close to the tube wall. In addition, cross-sectional averaged solids concentrations obtained on the basis of the optical measuring system and those obtained from the pressure gradient measurements showed satisfactory agreement.
\end{abstract}

Keywords: Solids concentration; Solids velocity; Gas-solid two-phase flow; Cold-flow circulating fluidized beds; Core-annulus structure

\section{Introduction}

Circulating fluidized beds (CFB) nowadays find a widespread application in a variety of industrial processes such as coal combustion and coal gasification, catalytic cracking of oil, and gas purification. Despite their widespread application the fluid mechanics of CFBs is unfortunately not very well understood. This can be attributed on one hand to the very complex hydrodynamics of these systems which complicates a thorough theoretical description and understanding and on the other hand to the vers significant difficulties encountered in measuring local fluid mechanic properties in dense gassolid two phase flows. Experimental studies clearly demonstrated the existence of inhomogeneous solids distributions in both axial and radial directions and the occurrence of solids downflow in the wall region [1-11]. In this study existing techniques for the measurement of solids concentration and solids velocity in gas-solid two phase flows will be briefly reviewed. In addition, a novel reflective optical probe system will be discussed which enables measurement of local solids concentration and local solids velocity. Subsequently detailed measurements will be presented which have been obtained from a small scale CFB unit for several mass fluxes of the gas and solid phase.

\section{Techniques for the measurement of solids concentration and solids velocity}

The only known device for direct measurement of the solids concentration employs quick closing valves with which the column of interest can be partitioned in sections of suitable length [12-14]. Typically within a fraction of a second the valves are closed, after which the solids contained in each section can be collected and weighed, yielding the solids concentration averaged over the volume of the section under consideration.

Neglecting wall friction and acceleration forces, the pressure drop over a certain section of a riser tubecan be attributed to gravity forces, according to the well-known manometer formula. This principle has been used by many investigators to measure the volume-average solids concentration $[9,12,15-18]$, despite the fact that for dilute systems and small tubes wall friction might play an important role. How- 
ever, Arena et al. [12] and Martin et al. [15] compared volume-averaged solids concentrations obtained from pressure drop profiles with values obtained using quick valves and tomography respectively. Both authors report satisfactory agreement.

Other measuring principles offer the possibility of determining the (axial) solids velocity as well, and they will be discussed subsequently.

\subsection{Optical techniques}

Ishida et al. [19], Ishida and Hatano [20] and Patrose and Caram [2]] developed reflective optica] probe systems which enable measurement of velocities of bubbles and individual particles in bubbling fluidized beds. Their probe systems basically consisted of two, vertically separated, sensors. Using these probe systems particle movement near gas jets in two-dimensional gas fluidized beds were studied. Measured particle velocities agreed well with results obtained on basis of laser doppler velocimetry (LDV), however the latter technique could not be applied in dense suspensions.

Kamiwano and Saito [22] developed an image sensor which enables measurement of particle velocities in fluidized beds. It consists of an array, either one-dimensional or twodimensional, of photodiodes $\left(50 \times 50 \mu \mathrm{m}^{2}\right)$. From the movement of the images of the particles on the image sensor the particle velocity could be determined. Saxena and Patel [23] used this reflective technique to obtain local solids concentrations near horizontal tubes immersed in air fluidized beds.

Hartge et al. [6,7,24-26] developed two optical probe systems. The first system was based on light absorption due to the presence of solid particles in a certain control volume between an emitting and a receiving fibre. The second system, containing both an emitting and receiving fibre, was based on light reflection due to particles present in front of the probe. The probe system based on the absorption of light only produced unambiguous signals for solids volume fractions not exceeding 0.25 , while the reflective system proved to be applicable up to packed bed conditions $\left(\epsilon_{s} \approx 0.6\right.$ ). However, Dyakowski and Williams [27] exploited the principle of light absorption. They used an optical device to measure the absorption of 8 light beams, passing through different chords in a certain cross-sectional area of a riser tube. By performing these measurements at two different heights and by applying an advanced cross-correlation technique the average solids velocity in dilute flows $\left(\epsilon_{s}<0.02\right)$ could be determined.

Many investigators used reflective optical probe systems [11,16,28-32] and employed different calibration techniques. As Hartge et al. [26] showed, the general relationship between solids concentration and output signal is given by:

$\Delta U=k \epsilon_{\mathrm{s}}^{n}$

where $\Delta U$ is the difference between the output signal measured in a two-phase (i.e. fluid-solid) system and the one obtained in the same fluid without solid particles being present. Rensner [32] showed that the power $n$ depends only on particulate phase properties whereas the factor $k$ also depends on the type of fluid and the characteristics of the electronic and optical components of the probe system. Because $n$ is independent of the fluid type, it is possible to determine the power $\boldsymbol{n}$ from calibration in water-solid mixtures which is very advantageous due to the fact that homogeneous watersolid suspensions can be generated easily. The factor $k$, which should be determined in an air-solids mixture, can be obtained subsequently by measuring the output signal in a packed bed of particles with an accurately known solids volume fraction.

Rch and $\mathrm{Li}$ [33] proposed a crossed fiber optical probe with a well-defined measuring volume and claimed improved performance in comparison with parallel optical probes. Ishii et al. [30] and Zhang et al. [16] suggested a non-linear relationship between solids concentration and the probe output signal $U$ according to:

$\epsilon_{\mathrm{s}}=C_{\mathrm{o}}+C_{1} U+C_{2} U^{2}+\ldots+C_{N} U^{N}$

They calibrated their probe using the mean voidage obtained from pressure drop measurements carried out at $(N+1)$ different operating conditions to produce $(N+1)$ equations for the unknown constants $C_{0} \ldots C_{N}$.

Kato et al. [11] assumed a linear relationship between solids concentration and their probe outpul signal. Subsequenuly they related this signal to the average solids concentration obtained from pressure drop measurements to obtain the unknown calibration constant.

\subsection{Laser doppler velocimerry}

Laser doppler velocimetry is based on the detection of optical interference phenomena, arising from two interacting laser beams. The light scattered by particles passing the interference spot ( fringe pattern) is collected by a photomultiplier delector, producing a doppler signal at the detector output. Because the detected signals originate from individual particles, these signals also contain the necessary information for obtaining particle size and particle concentration as demonstrated by Yianneskis [34]. For low solids concentration ( $\epsilon_{\mathrm{s}}<0.01$, depending on traversing length), the technique is non-inisusive [35-38] which is unfortunately not the case for higher solids concentrations where probes are required to penetrate the suspension under consideration $[36,39]$.

\subsection{Techniques using fluorescent particles}

Techniques using fluorescent particles offer the same advantages as techniques using radioactive particles, but are generally much cheaper. A disadvantage, however, is the strong reduced observability in dense particulate flows.

Brewster and Seader [40] measured particle velocities in a co-current down flow of a gas-solid mixture by injecting fluorescent particles, which upon irradiation with UV light emitted visible light that was subsequently detected by external sensors positioned at different heights. Kojima et al. [41] 
also used this technique to measure solids velocity in the centre of a tube in a pneumatic conveying line. Morooka et al. [42] studied the movement of fines (FCC catalyst coated with fiuorescent dye) in a fluidized bed of larger particles. Different probes were used simultaneously to observe the movement of the fines.

To enable discrimination between different kinds of particles, Hamdullahpur et al. [43] employed a fluorescence technique in their LDV measurements. Light scattered by particles coated with a fluorescent dye also possessed a wavelength other than the wavelength that was used for the LDV light source. Appropriate filtering of the scattered light signals made it possible to determine the velocities of the different particles used in their gas-solid flow. By adding small tracer particles, the dynamic gas velocity could also be determined.

\subsection{Strain gauges}

Mann and Crosby [44] developed a strain gauge nicroprobe to measure local particle concentrations and velocities in gas-solid two-phase flows. Their probe contained a small piezo-electric transducer and was designed to register impact of individual particles. The local particle flux was obtained from the number of collisions per unit time where the proportionality factor could be related to the known average solids mass flux. However, to obtain solids velocities a calibration method was required. Mann and Crosby therefore dropped particles from different heights onto the transducer, meanwhile determining the velocity with a high speed video camera and recording the transducer output signal.

Raso et al. [45] developed a strain gauge micro-probe based on the same principle as the one used by Mann and Crosby. With their needle probe $(\varnothing=6 \mathrm{~mm})$ they were able to register single particle impacts. The solids concentration followed from the impact frequency, while the solids velocity was obtained from the force acting on a strip of deformable material with strain gauges glued on its surface.

\subsection{Electrostatic probes}

Due to impacts with walls, solid particles acquire an electrical charge when they flow through a conduit. Therefore, a probe inserted in the particle flow will develop an electrical charge at a rate which is proportional to the solids mass flow. Soo et al. [46] developed an electrostatic ball proke based on this principle. The proportionality factor was obtained from the velocity in the centre of the tube, which they assumed to equal the empty pipe velocity, and the measured particle concentration measured in the tube centre using an optical technique. Klinzing et al. [47] used the same principle to measure the solids mass flow and velocity, but developed a non-intrusive device. Their probe consisted of a coil wound around the transport tube under investigation. The magnitude of the induced electrical current is a measure for the solids mass flow. Klinzing et al. studied the pneumatic transport regime and by cross-correlating signals obtained from two coil probes with a known axial separation they were able to obtain the axial velocity of the particles. Gajewski et al. [48501 used a similar technique, but in addition they were able to obtain information regarding the fluctuation of the solids mass flow rate.

\subsection{Capacitive probes}

Capacitive probes usually consist of two small rectangular plates, separated from each other by a small gap. Local changes in solids concentration in the gap alter the dielectrical constant of the phase present between the two plates and thereby change the capacitance of the system.

Hartge et al. [6,7] used a capacitance needle probe to measure the local solids concentration in a $40 \mathrm{~cm}$ diameter CFB. Despite the fact that the walls were made of steei, they experienced experimental difficulties due to electrostatic charging. Despite these problems Herb et al. [51] applied a capacitance probe, consisting of two triangular electrodes, to measure the solids volume fraction as a function of radial position in a CFB.

Riley and Louge [52] used two probe configurations to measure local solids concentration in gas-solid two-phase tube flow: one for far-wall measurements and the other a nonintrusive design mounted in the wall to perform voidage measurements in the vicinity of the wall. In a later study, Louge et al. [53] used the first-mentioned probe configuration to measure local solids concentration in the wall region of a circulating fluidized bed.

\subsection{Sampling or extracrion probes}

Although sampling or extraction probes are based on a relatively simple measuring priaciple, the sucecss of their use depends on very subtle factors which hamper their widespread application. These probss are usually based on isolation of solid particles from the main stream by inserting a small tube in the gas-solids flow while imposing an aspiration rate through the tube which corresponds to the local gas velocity that would exist at that particular position if the probe were not present. This operation mode of the sampling or extraction probe is known as isokinetic sampling. By collecting the withdrawn particles in a collection bottle during a certain time the local mass flow rate of the particles can be determined.

Van Breugel et al. [1] operated a sampling probe under isokinetic conditions to measure the upward and downward solids mass fluxes but Gajdos and Bierl [54] applied the nonisokinetical operation mode. They assumed that the upward and downward flux components can be obtained by extrapolating the measured mass flux versus extraction gas flow rate to zero gas extraction flow rate. Neither Monceaux et al. [8] nor Bader et al. [9] operated under isokinetic conditions. They found that for sufficiently high aspiration rates the measured flux was independent of the extraction flow rate. 


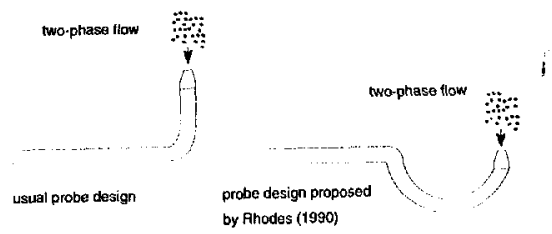

Fig. I. Sampling probe design proposed by Rhodes [55].

Rhodes [55] measured solids mass fluxes using a nonisokinetic sampling probe similar in approach to Gajdos and Bierl and also arrived at the conclusion that isokinetic sampling is not necessary. In addition, Rhodes improved the probe design of Gajdos and Bierl because in the latter study the tip of the probe was in different axial positions when measuring upward and downward fluxes. As may be clear from rig. 1 the probe design of Rhodes eliminaled this disadvantage. However, with their design it is not possible to make measurements in the neighbourhood of the tube wall.

Despite this disadvantage Harris et al. [56] used this probe type to measure local solids mass fluxes under isokinetic conditions. Close to the wall it was not always possible to maintain isokinetic conditions because the probe choked at low gas extraction flow rates. The same probe was also used as a Pitot-tube, neglecting the kinetic energy contribution of the gas phase. The combination of these techniques made possible the simultaneous determination of solids velocity and solids concentration.

Herb et al. [57] measured both upward and downward solids mass fluxes as a function of radial position. Crosssectional averaging of the local mass flux yielded an overall mass flux that was within $10 \%$ of the value obtained from an integral mass flux measurement in the return leg of the CFB. Due to isokinetic operation of their probe, in addition the local gas phase velocity could be determined. Herb ct al found that the measured mass fluxes were not strongly dependent on the extraction gas flow rate near the isokineticul operation condition.

Miller and Gidaspow [58] also applied an extraction probe to determine local solids mass fluxes. Although the upward and downward mass fluxes were sensitive to the extraction flow rate, the net mass flux appeared to be independent of the extraction How rate. According to Miller and Gidaspow it is not necessary to measure under isokinetical conditions, which, besides, they consider as almost impossible to do so due to large and rapid velocity fluctuations of the gas-solid flow.

\subsection{Radioactive tracer particles}

Radiosctive tagging offers the possibility of measuring the solids velocity directly, without the necessity of calibration. In addition, effects of particle size and shape can be investigated by injecting tagged particles with a pre-selected size and/or shape.
Lin et al. [59] used radioactive tracer particles to study the motion of solids in gas fluidized beds. Gamma radiation emitted by tracer particles was continuously monitored by twelve scintillation detectors located around a cylindrical gas fluidized bed $(\varnothing=12 \mathrm{~cm})$, and provided information on the instantaneous particlc locations.

Viitanen [60] measured velocities of both phases in a riser tube of a CFB using a radioactive isotope of argon ( ${ }^{41} \mathrm{Ar}$ ) as tracer for the gas phase while the FCC catalyst contained ${ }^{140} \mathrm{La}$. Following the injection of tracer particles, their propagation was followed using fifteen thallium-activated sodium iodide ( $\mathrm{NaI}$ ) scintillation detectors.

\subsection{X-ray and $\gamma$-ray techniques}

Bartholomew and Casagrande [61] used a $\boldsymbol{\gamma}$-ray absorption technique to determine the radial distribution of solids concentration in a fully developed riser flow. They measured the extent of $\gamma$-ray absorption along eighteen different chords at a fixed axial position in the riser tube and from this information they were able to determine the radial solids concentration profile.

Berker and Tulig [62] described a procedure for obtaining radial solids concentration profiles by measuring the extent of $\gamma$-ray absorption along different chords in a fixed crosssection of the column and subsequent application of a deconvolution technique to solve the integral equation relating the measured $\gamma$-ray attenuation along the chords to the radial solids concentration profile.

As Hartge [26] pointed out, $\boldsymbol{\gamma}$-ray densitometry yields mean solids concentrations that are not identical to the true cross-sectional averaged solids concentrations because this technique measures a quantity which represents an average over the measured chord which does not equal the value obtained with $\gamma$-ray absorption. In addition to $\gamma$-ray densitometry, tomography has been used to determine the spatial distribution of solids concentration in CFBs [25,63]. Although this measuring technique produces detailed and accurate data it has not found widespread application due to the considerable cost of the equipment.

Besides $\gamma$-ray absorption, $\mathrm{X}$-ray absorption techniques have becn applied to determine solids concentrations in CFBs. For instance, Grohse [64] and Weinstein et al. [3] applied $\mathrm{X}$-ray cameras in a non-intrusive mode by measuring the $\mathrm{X}$-ray attenuation along different chords in a fixed crosssection of the column. From these data, they obtained the solids concentration as a function of the radius. Miller and Gidaspow [58] measured solids concentrations in a riser tube using a X-ray camera containing a copper isotope $\left({ }^{244} \mathrm{Cu}\right)$. To obtain local solids concentrations they inserted a probe in their system.

\subsection{Acoustic methods}

Sheen and Raptis [65] reported two acoustic sensing techniques that can be applied to measure the velocity of particles 
in a gas-solid pneumatic transport line. One of these techniques is based on detection of the noise generated due to particle-wall and inter-particle collisions. On the basis of a comparison with results obtained from a radioactive particle tracking technique, they showed that the measured noise levels possessed a linear dependence with respect to particle velocity. Because the noise level additionally increased with increasing solids concentration, another technique was required to determine the solids concentration.

Application of the other technique allowed for a direct measurement of the solids velocity. Two sensors, with a known axial separation, both received signals that were emitted from the opposite tube wall. Due to interference of the particulate phase with these signals they possessed modified frequencies which upon cross-correlation yielded the particle velocity. Velocities determined in this way were roughly twothirds of the values determined with the radioactive particle tracking technique. The authors attributed this discrepancy to the fact that the cross-correlating technique predominantly detects particles moving close to the tube wall, while the radioactive method detects particles moving near the centre region.

The techniques discussed in this section, are compared in Table 1 . In addition, some remarks are given about their advantages and disadvantages.

\section{Development of an optical probe system}

To measure both the local solids concentration and the local axial solids velocity, a reflective optical probe has been developed which is roughly based on the same principle as the one developed by Hartge et al. [24]. To improve the quality of the signals the monoglass fibre, as used by Hartge et al., has been replaced by a bifurcated multi-glass fibre (diameter of glass fibres: $15 \mu \mathrm{m}$ ). This eliminated the necessity of using a beam splitter which considerably weakens the light signals. To enable measurement of the local solids velocity, the optical probe consists of two sensors with a vertical separation of $4.2 \mathrm{~mm}$. Vertically moving particles, in principle, pass both sensors, causing the two sensors to produce similar signals with the difference of only a shift in time. The time delay, obtained by cross-correlating both signals, yields the velocity of the particles moving in front of the probe tip. Fig. 2 shows the optical measurement system in more detail. For both sensors light, emitted by laser diodes (power: $25 \mathrm{~mW}$; light: $\lambda=685 \mathrm{~nm}$ ), is guided to the probe tip by half of the glass fibres of the multi-glass fibre. Part of the reflected light is guided by the other half of the glass fibres to photodiodes (area: $3 \times 3 \mathrm{~mm}^{2}$, sensitivity: $80 \mathrm{nA} / \mathrm{lux}$ at $\lambda=880$ nm) which convert the optical signals into electrical signals. Subsequent amplification of the photo diode signals deliver voltage signals as a function of time amenable to further processing with a personal computer.
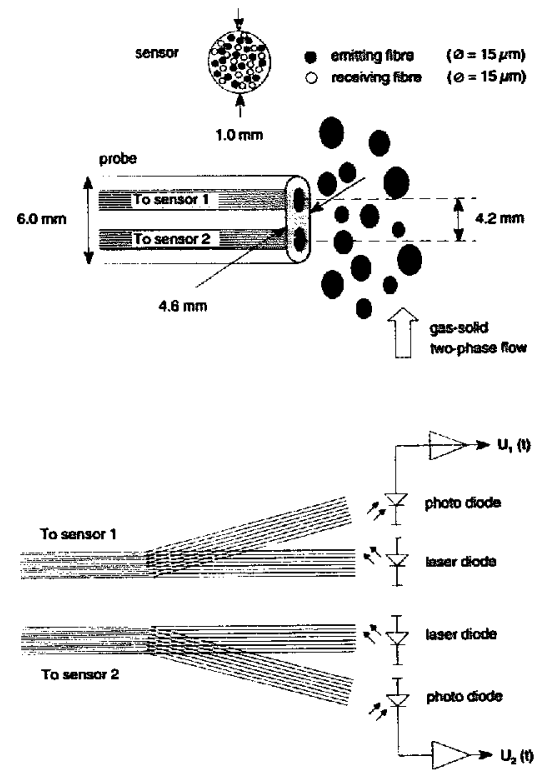

Fig. 2. Schenatic representation of the optical probe system, containing two multi-fibre sensors.

\subsection{Validation and calibration}

The band width of the optical measuring system has been tested using a light emitting diode (LED) flashing at high frequency. Up to frequencies of $100 \mathrm{kHz}$ the system was able to detect the test signal correctly.

As Hartge et al. [24] showed, the relation between the amplified output yoltage $U$ of the photo diode and the local particle concentration $\epsilon_{\mathrm{s}}$ is given by:

$U=U_{0}+a e_{s}^{b}$

provided that a monoglass fibre is used to guide the light. In this equation $U_{0}$ represents the voltage signal which is obtained in the pure carrier fluid, while for transparent fluids the value of the exponent $b$ only depends on the characteristics of the particulate phase. This offers the advantageous possibility to calibrate the optical probe in sand-water mixtures. The optical probe has been calibrated with both water and poly(ethylene) glycol (PEG) as continuous phase, the results are shown in Fig. 3. From this figure it can be seen that similar values for the exponent $b$ are found, although the physical properties of both continuous phases differ strongly. The value of the constant $a$ follows from a measurement in a packed bed with known solids volume fraction. 


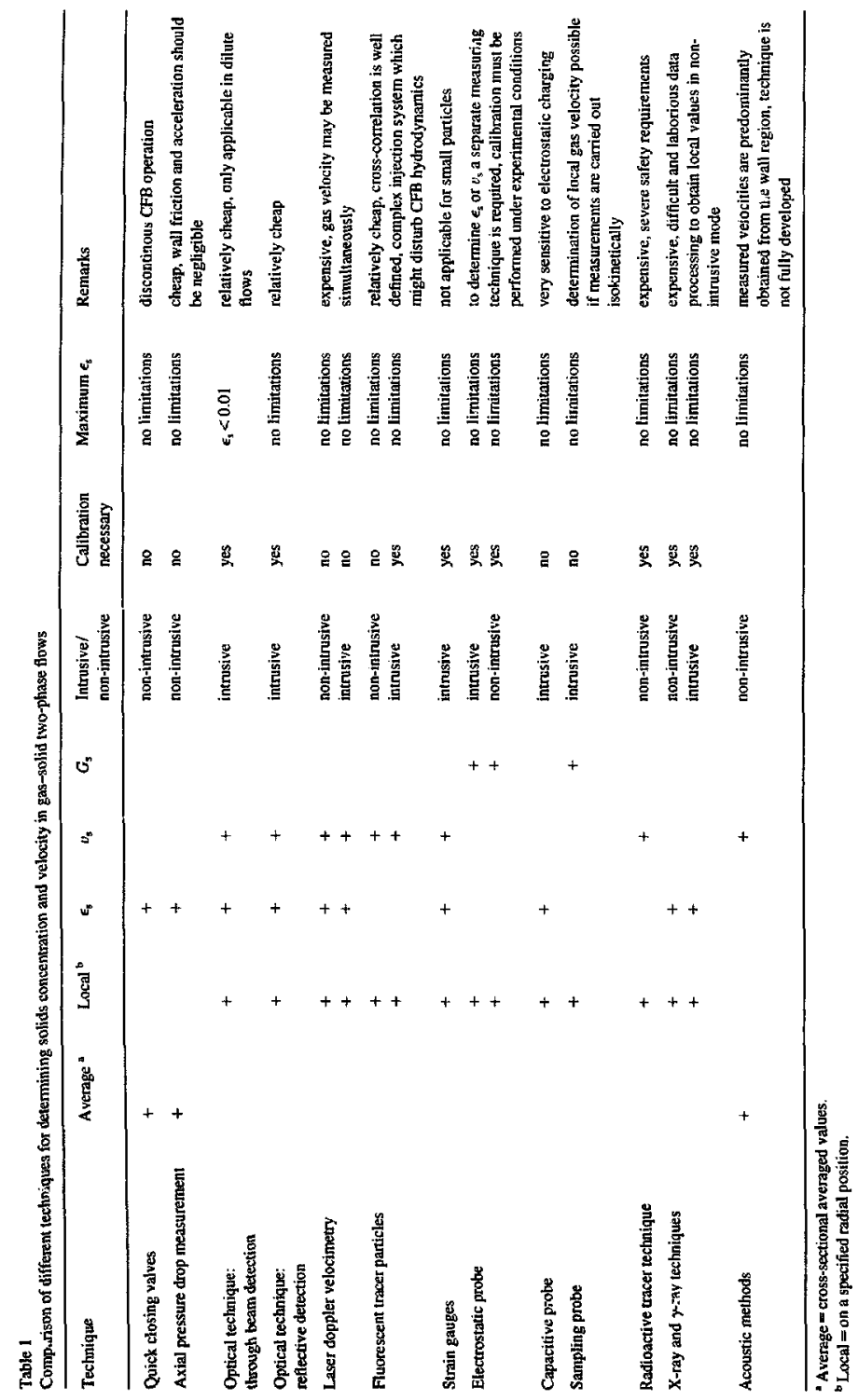




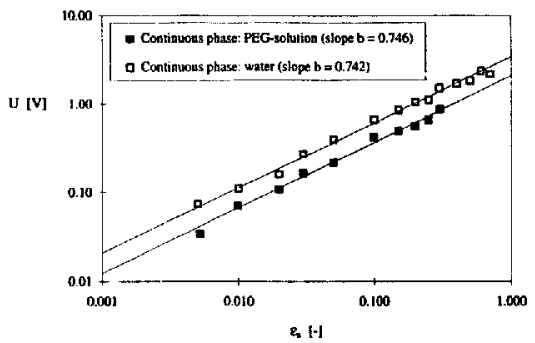

Fig. 3. Calibration curves for the optical measuring system. Both water and PEG have been used as continuous phase, showing no effect on the exponent $b$ (slope of line).

The effective distance between the centres of both sensors followed from a calibration with a rotating white disc with random plotted black dots on it. A stroboscope was used to determine the exact rotation speed of this disc. The calculated velocity, obtained by cross-correlating both recorded signals [66], yielded correct values for a distance $\Delta x$ of $4.2 \mathrm{~mm}$ between both sensor tips.

\subsection{Signal processing}

In this study, typically, measurements were performed at eleven radial positions. At each position $m$ measurements were made $(30<m<40$ ), where for each measurement 1536 samples were taken with a maximum sample frequency $f$ of $50 \mathrm{kHz}$. The local solids concentration $\epsilon_{s}$ was calculated from the individual sensor signals as follows:

$\overline{\epsilon_{\mathrm{s}}}=\frac{1}{N} \sum_{i=1}^{N}\left(\frac{\Delta U_{i}}{a}\right)^{1 / b}$

where the total number of samples $N$, equals 1536 times $m$. One would expect that processing of both sensor signals yields the same solids concentration, however, it tumed out that the upper sensor (sensor 1 in Fig. 2) always produced significantly lower solids concentrations than the lower sensor. Probably this difference is due to splitting of the two phase flow due to insertion of the probe. In this study, the average of both sensor signals has been used to cietermine local solids concentrations.

As mentioned before, the local solids velocity can be obtained by cross-correlating the signals of both sensors. In this study a discrete cross-correlation technique, employing fast Fourier transformation, has been applied [66] to determine the time shift $\tau$ between both signals.

Due to local fuctuations of the solids phase velocity there exists no unique time shift between both signals, but rather a time shift distribution and corresponding a solids phase velocity distribution. To obtain this velocity distribution the signals were divided into $p$ blocks, containing 256 to 1024 sample points. The signals contained in these individual blocks were subsequently cross-correlated with the signal of the other sensor to yield the velocity $v_{i}$ (see Eq. (5)) corresponding to the selected individual block. Of course this procedure cannot be followed for the outer blocks, since a time shift in both directions of the time domain is in principle possible.

$v_{i}=\frac{\Delta x}{\tau_{i}}$

Following this procedure $(p-2)$ times, $m$ individual velocities were calculated, with $p$ the number of blocks in which the first signal was divided. The local solids phase velocity was finally obtained from:

$\bar{v}=\frac{\overline{G_{\mathrm{s}}}}{\rho_{\mathrm{s}} \overline{\epsilon_{\mathrm{s}}}}=\frac{\sum_{i=1}^{(p-2) m} \epsilon_{\mathrm{s}, i} \nu_{i}}{\sum_{i=1}^{(p-2) m} \epsilon_{\mathrm{s}, i}}$

Note that this particular type of averaging of the individual velocities uses the solids volume fraction as a weighing factor.

To obtain a proper cross-correlation, the blocks should contain sufficient data points to display a characteristic pattern. To amplify these patterns, the mean value of the signals was subtracted from instantaneous signals before performing the cross-correlation of both signals, where the mean signal is given by:

$\bar{U}=\frac{1}{N} \sum_{i=l}^{N} U_{i}$

In this study, a typical block length of 256 data points $(p=6)$ has been used, to allow for a shift of 256 data points in both directions of the time domain.

\section{Experimental equipment}

In this study, the hydrodynamics of a small scale circulating fluidized bed unit, schematically shown in Fig. 4, has been studied. This unit consists of a steel storage vessel ( $L=4.0 \mathrm{~m}, D=0.6 \mathrm{~m}$ ), a transparent PVC riser tube ( $L=$ $8.0 \mathrm{~m}, D=0.054 \mathrm{~m}$ ) and two cyclones to separate the solids from the main gas stream. Sand particles $\left(d_{\mathrm{p}}=129 \mu \mathrm{m}\right.$, $\rho_{s}=2540 \mathrm{~kg} \mathrm{~m}^{-3}$ ) were kept at incipient fluidization in the storage vessel. This vessel contained $1000 \mathrm{~kg}$ of sand particles, which corresponds to several hundred times the maximum solids hold up in the riser column. Solid particles were fed to the riser column through a connection tube $(L=1.0 \mathrm{~m}$, $D=0.054 \mathrm{~m}$ ), mounted under an angle of $45^{\circ}$ with respect to the riser column. The solids mass flux could be controlled with a slide valve, mounted halfway in the connection tube. Just above the solids entry a solids distributor was included in the riser tube to achieve a uniform distribution of the solids over the tube cross-sectional area. This distributor was made of six staggered layers, each consisting of five pieces of 1.5 mm diameter steel wire positioned parallel to each other. To 


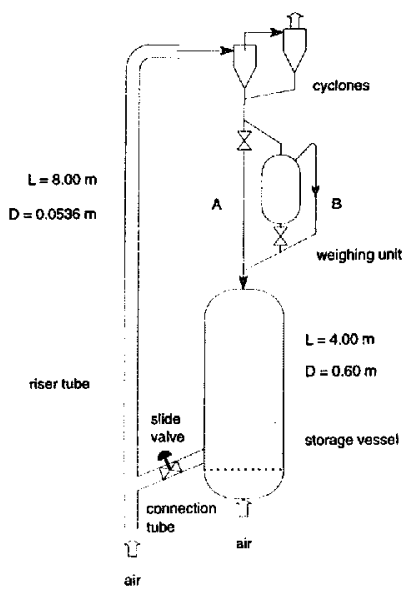

Fig. 4. Schematic representation of the small scale $\mathrm{CFB}$ unit

convey the solid particles, humidified air ( $\mathrm{RH}=80 \%)$ was supplied at the bottom of the riser tube, its flow being controlled by a rotameter. At the exit of the riser column two cyclones separated the solids from the fluidizing air, where the separated solid particles were fed back to the storage vessel after having passed a weighing unit.

At a height of $1.8 \mathrm{~m}$ above the solids distributor a stuffing box packing, mounted on the riser wall, enabled on-line displacement of the optical probe over the entire diameter of the riser column. The relevant section of the riser tube was cov. ered with black cloth to prevent interference from external light.

In axial direction sixteen pressure taps were mounted in the wall of the riser column with an equidistant spacing of $47 \mathrm{~cm}$. To minimize any possible disturbing effect on local CFB hydrodynamics due to the presence of the pressure tap, the concept, as shown in Fig. 5, was used. Pressure differences over the fiftcen sections were measured using water manometers $(H=2.5 \mathrm{~m})$.

The mass flow rate of the circulating solids could be deter mined by collecting the solids in a weighing unit, which was connected to a dynamo meter, during a certain period of time. Typically, $25 \mathrm{~kg}$ portions of sand particles were collected in the weighing unit, while the gas was bypassed (route $B$ in Fig. 4) to prevent pressure build-up.

\section{Results}

Fig. 6 shows the experimentally-determined pressure gradient as a function of height for a superticial gas velocity $u^{\mathrm{\nu}}$ of $10 \mathrm{~m} \mathrm{~s}^{-1}$ and solids mass fluxes $G_{\mathrm{s}}$ of $100,200,300$ and

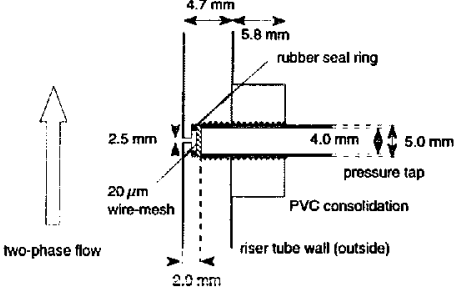

Fig. 5. Schematic representation of a pressure lap, designed to minimize any possible disiurbing influence on local hydrodynamics of the gas-solid twophase flow.

$400 \mathrm{~kg} \mathrm{~m}^{-2} \mathrm{~s}^{-1}$. The momentum loss per unit volume, represented by the pressure gradient, is caused by forccs arising from acceleration effects and gravity and wall friction forces acting on both phases:

$-\frac{\mathrm{d} P}{\mathrm{~d} z}=G_{\mathrm{f}} \frac{\mathrm{d} u}{\mathrm{~d} z}+G_{\mathrm{s}} \frac{\mathrm{d} v}{\mathrm{~d} z}-\epsilon_{\mathrm{f}} \rho_{\mathrm{t}} g-\epsilon_{\mathrm{s}} \rho_{\mathrm{s}} g+F_{\mathrm{w}, \mathrm{l}}+F_{\mathrm{w}, \mathrm{s}}$

In this equation $F_{w, f}$ and $F_{w, s}$ represent the friction force acting on the tube wall, per unit volume gas-solid mixture, by the gas phase and solid phase respectively.

As may be clear from Fig. 6 the acceleration of solids, with accompanying decrease in axial solids concentration due to the requirement of constant solids mass flux, causes a decrease in pressure gradient in the bottom region of the riser. This phenomenon can be observed very clearly for solids mass fluxes of 300 and $400 \mathrm{~kg} \mathrm{~m}^{-2} \mathrm{~s}^{-1}$. Beyond the accelcration zone, the pressure gradient attains a constant value, implying that wall friction and gravity forces completely dominate the momentum loss. For systems with relative high solids concentration and moderate transport velocities, the friction with the tube wall can be neglected, which offers the advantageous possibility of determining the average solids concentration from the pressure gradient (see Section 2.2) above the acceleration zone.

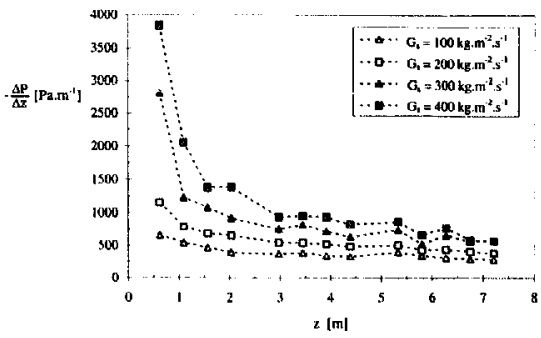

Fig. 6. Experimentally-determined pressure gradient as a function of height for four solids mass fluxes; $u^{\circ}=10 \mathrm{~m} \mathrm{~s}^{-1}$. 


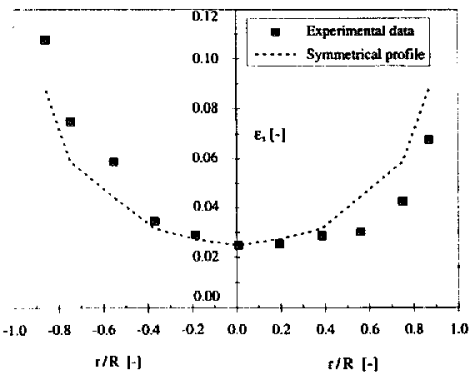

Fig. 7. Local solids concentration as a function of dimensionless radial position at $1.8 \mathrm{~m}$ above the solids distributor, $u^{\mathrm{n}}=10 \mathrm{~m} \mathrm{~s}^{-1}, \mathrm{G}_{\mathrm{s}}=300 \mathrm{~kg}$ $\mathrm{m}^{-2} \mathrm{~s}^{-1}$.

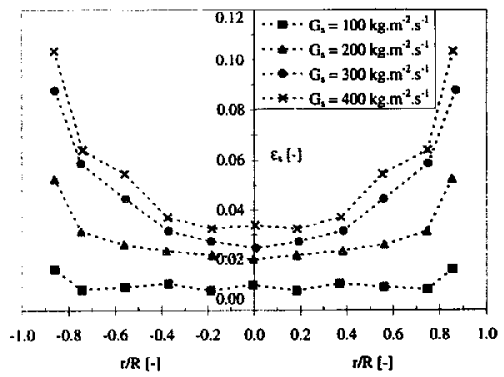

Fig. 9. Local solids concentration as a function of dimensionless radial position at $1.8 \mathrm{~m}$ above the solids distributor for four solids mass fluxes; $\omega^{\circ}=10 \mathrm{~ms}^{-1}$.

The length of the acceleration zone increases with increasing solids mass flux, as evident from Fig. 6.

Fig. 7 shows the radial distribution of the solids concentration, measured with the optical probe system at a height of $1.8 \mathrm{~m}$ above the solids distributor for $u^{0}=10 \mathrm{nin} \mathrm{s}^{-1}$ and $G_{\mathrm{s}}=300 \mathrm{~kg} \mathrm{~m}^{-2} \mathrm{~s}^{-1}$. From this figure, it can be concluded that the radial solids concentration profile is asymmetrical. However, the same asymmetrical profile was found when the probe was inserted from the opposite direction in the riser tube, indicating that the observed asymmetry in Fig. 7 is a property of riser hydrodynamics and is not caused by disturbance of local hydrodynamics due to insertion of the optical probe. For convenience, further radial profiles will be shown in symmetrical form by averaging the measured solids volume fraction at identical distances from the centre line of the lube.

In Fig. 8 the radial solids concentration is plotted versus the dimensionless radial coordinate for different solids mass fluxes and a superficial gas velocity $u^{\circ}=10 \mathrm{~ms} s^{-1}$. As evident from this figure and from Fig. 9, showing the normalized

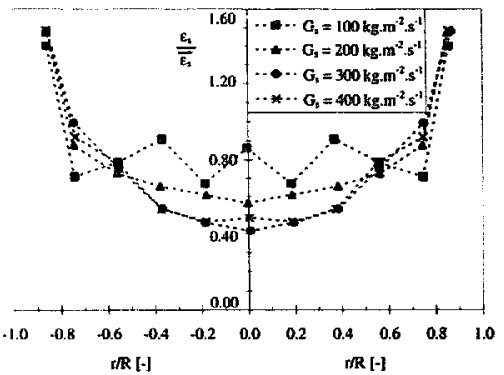

Fig. 9. Normalized solids concentration (i.e. local concentration divided by cross-sectional averaged concentration) as a function of dimensionless radial position at $1.8 \mathrm{~m}$ above the solids distributor for four solids mass fluxes; $u^{\circ}=10 \mathrm{~m} \mathrm{~s}^{-1}$.

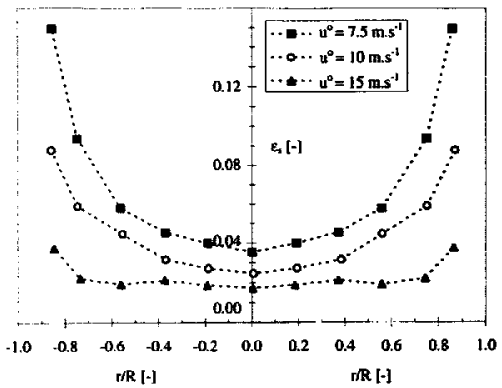

Fig. 10. Local solids concentration as a function of dimensionless matial position al $1.8 \mathrm{~m}$ above the solids distributor for three superficial gas velocities; $G_{\mathrm{s}}=300 \mathrm{~kg} \mathrm{~m}^{-2} \mathrm{~s}^{-1}$.

solids concentration profiles (i.e. local value divided by mean value), the extent of lateral solids segregation increases with increasing solids mass flux. The same dependence has been reported by Martin et al. [15] and Kato et al. [11]. Fig. 10 shows local solids concentration profiles obtained at three superficial gas velccities $\left(u^{\circ}=7.5,10\right.$ and $15 \mathrm{~m} \mathrm{~s}^{-1}$ ) for a constant solids mass flux $G_{\mathrm{s}}$ of $300 \mathrm{~kg} \mathrm{~m}^{-2} \mathrm{~s}^{-1}$. As evident from this figure, with decreasing gas velocity and constant solids mass flux, a more pronounced lateral solids segregation results, which is in accordance with the observations of Weinstein et al. [3].

Fig. 11 shows the axial solids velocity as a function of the dimensionless radial coordinate, and corresponds to the radial distributions of solids concentration depicted in Fig. 8. From this figure it can be seen that, in agreement with observations from Yang et al. [38], the solids mass flux only slightly infuences the solids velocity profile. Fig. 12 shows the radial distributions of axial solids velocity for several gas velocities obtained at a solids mass flux $G_{s}$ of $300 \mathrm{~kg} \mathrm{~m}^{-2} \mathrm{~s}^{-1}$. As may 


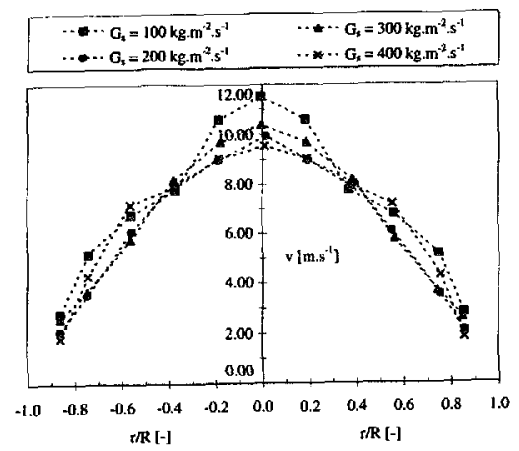

Fig. 11. Axial solids velocity as a function of dimensionless radial position at $1.8 \mathrm{~m}$ above the solids distributor for four solids mass fluxes $u^{\circ}=$ $10 \mathrm{~ms}^{-1}$.

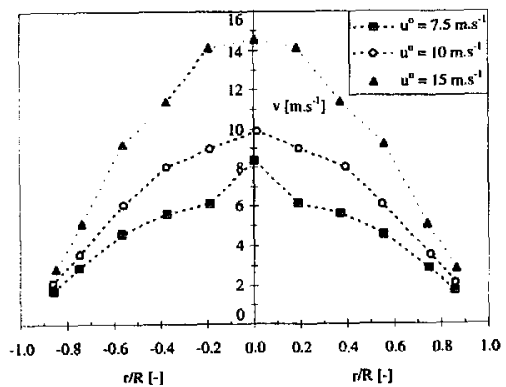

Fig. 12. Axial solids velocity as a function of dimensionless radial position at $1.8 \mathrm{~m}$ above the solids distributor for three superficial gas velocities; $G_{\mathrm{s}}=300 \mathrm{~kg} \mathrm{~m}^{-2} \mathrm{~s}^{-1}$.

be expected, the solid phase velocity increases with increasing gas velocity. The shape of the parabolic profiles, however, almost remains the same as can be seen in Fig. 13, showing normalized velocity profiles (i.e. local solid phase velocity divided by the superficial gas velocity).

To provide a check with respect to the measured distributions of solids concentration and solids velocity, the average solids mass flux $G_{\mathrm{s}}^{*}$ calculated from:

$G_{s}^{*}=\frac{1}{\pi R^{2}} \sum_{i} 2 \pi r_{i} \epsilon_{\mathrm{s}, i} \rho_{s} v_{i} \Delta r_{i}$

has been compared with the imposed solids mass flux $G_{\mathrm{s}}$. Table 2 shows the results obtained on basis of this comparison for several operating conditions. From this table it can be seen that in general the error is less than $25 \%$, but in all cases the average solids mass flux calculated from the data measured with the optical probe $G_{\mathrm{s}}^{*}$ exceeds the imposed solids mass

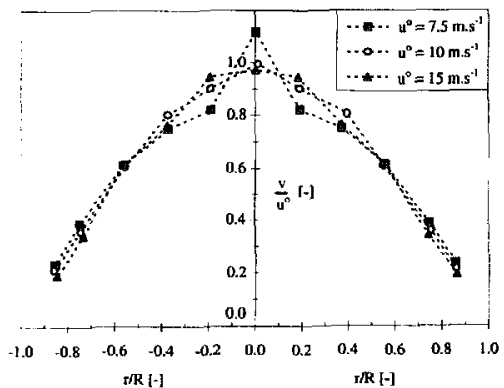

Fig. 13. Normalized axial solids velocity (i.e. $v / u^{v}$ ) as a function of diraensionless radial position al $1.8 \mathrm{~m}$ above the solids distributor for three superficial gas velacities; $G_{\mathrm{s}}=300 \mathrm{~kg} \mathrm{~m}^{-2} \mathrm{~s}^{-1}$.

Table 2

Comparison between the average solids mass flux $G_{*}^{*}$ determined with the optical measuring system and the imposed solids mass flux $G_{\mathrm{s}}$

\begin{tabular}{llll}
\hline $\begin{array}{l}a^{\mathrm{D}} \\
\left(\mathrm{m} \mathrm{s}^{-1}\right)\end{array}$ & $\begin{array}{l}G_{\mathrm{s}} \\
\left(\mathrm{kg} \mathrm{m}^{-2} \mathrm{~s}^{-1}\right)\end{array}$ & $\begin{array}{l}G_{\mathrm{s}}^{*} \\
\left(\mathrm{~kg} \mathrm{~m}^{-2} \mathrm{~s}^{-1}\right)\end{array}$ & $\begin{array}{l}\text { Emor } \\
(*)\end{array}$ \\
\hline 10 & 100 & 120 & 20 \\
10 & 200 & 235 & 15 \\
10 & 300 & 374 & 25 \\
10 & 400 & 436 & 9 \\
7.5 & 300 & 443 & 48 \\
15 & 300 & 350 & 17 \\
\hline
\end{tabular}

fux $G_{\mathrm{s}}$. This discrepancy can possibly be attributed to solids downflow close to the tube wall, a phenomenon which will decrease the net solids mass flux. In the case of the lowest gas velocity $\left(u^{\circ}=7.5 \mathrm{~m} \mathrm{~s}^{-1}\right)$ this effect will manifest itself most pronounced, generating the relatively large difference of $48 \%$. During the experiments such a downward flow of particles has been observed visually through the transparent wall of the riser column. Due to encapsulation of the optical probe with sand particles, it was impossible to measure in the outer $3 \mathrm{~mm}$ of the tube radius. In addition, it should be mentioned that the calculation is rather inaccurate due to the small number of measuring points.

Furthermore, the cross-sectional average solids concentration $\epsilon_{\mathrm{s}}^{*}$ :

$\epsilon_{\mathrm{s}}^{*}=\frac{1}{\pi R^{2}} \sum_{i} 2 \pi r_{i} \epsilon_{\mathrm{s}, i} \Delta r_{i}$

has been compared to the average solids concentration which was obtained from the axial pressure gradient. This procedure can only be justified in the case where friction with the tube wall and acceleration effects can be neglected. Fig. 14 shows a parity plot of the cross-sectional averaged solids concentration obtained with the optical measuring system and the solids concentration obtained from the pressure gradient measurements. For the case with $u^{\circ}=15 \mathrm{~m} \mathrm{~s}^{-1}$ and $G_{\mathrm{s}}=$ 


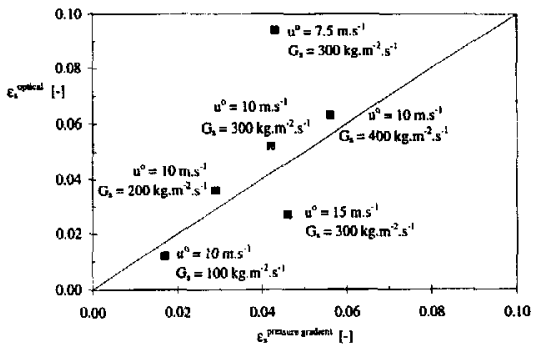

Fig. 14. Comparison of average solids concentration (determined irom pressure gradient meosurements) with cross-sectional ayeraged solids concer!tration obtained from the optical measuring system.

$300 \mathrm{~kg} \mathrm{~m}^{-2} \mathrm{~s}^{-1}$ the cross-sectional averaged solids concentration determined from the axial pressure gradient significantly exceeds the value obtained from the optical measuring system. As can be seen in Fig. 6, measurements with the optical probe have been performed in the acceleration zone where solids acceleration contributes significantly to the axial pressure gradient. Additionally, for high velocities the friction with the tube wall will considerably contribute to the axial pressure gradient. When these phenomena are not considered in the interpretation of the pressure gradient measurements the value of the obtained solids concentration will be to high but for the case with $u^{0}=7.5 \mathrm{~m} \mathrm{~s}^{-1}$ and $G_{\mathrm{s}}=300$ $\mathrm{kg} \mathrm{m}^{-2} \mathrm{~s}^{-1}$, the cross-sectional averaged value of the solids concentration determined from the axial pressure gradient significantly underpredicts the value obtained on basis of the optical measuring system. At such a low gas velocity, considerable downflow may be expected resulting in a negative frictional contribution to the pressure drop which causes underestimation of solids concentration in case friction with the tube wall is neglected. In this case the effect due to friction with the tube wall dominates the effect due to acceleration of the solids (Fig. 6) which leads to an overestimate of the solids concentration.

\section{Conclusions}

A brief review of tcchniques employed previously for measuring solids concentration and solids velocity in (dense) gas-solid two-phase flow has been presented. An optical measuring system, similar in concept to the one proposed by Hartge et al. [24], has been developed. Using this system, the flow structure in a cold-flow CFB unit has been investigated by measuring local solids concentration and local axial solids velocity as a function of the radial position in the riser tube.

With increasing solids mass flux at constant superficial gas velocity, or alternatively with decreasing superficial gas velocity at constant solic : mass flux, the lateral solidis segregation becomes more pronounced. Furthermore, the axial solids velocity profile showed a weak dependence with respect to solids mass flux. A decreasing superficial gas velocity caused a decrease in solids velocity although the shape of the profiles was relatively unaffected.

It turned out that solids mass fluxes calculated from the local values of solids concentration and solids velocity exceeded the imposed solids mass fiux. The downflow observed visually of solid particles close to the tube wall offers a possible explanation for this discrepancy. However, the two solids mass fluxes agree within $25 \%$ error.

In addition cross-sectional averaged solids concentrations obtained on the basis of the optical measuring system have been compared with solids concentrations obtained from pressure gradient measurements using the well-known manometer formula. The agreement was reasonable, except for the cases with the lowest and highest superficial gas velocities $\left(u^{\circ}=7.5\right.$ and $\left.15 \mathrm{~m} \mathrm{~s}^{-1}\right)$. For these cases it is not allowed to neglect the momentum loss contributions due to friction with the tube wall and solids acceleration.

\section{List of symbols}

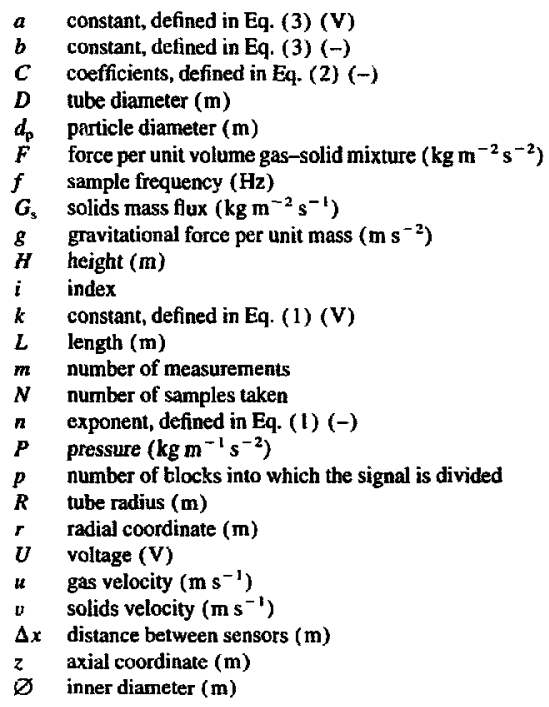

\section{Greek letrers}

$\epsilon \quad$ volume fraction (-)

$\lambda$ wave length $(\mathrm{m})$ 
$\begin{array}{ll}\rho & \text { density }\left(\mathrm{kg} \mathrm{m}^{-3}\right) \\ \tau & \text { lime shift (s) }\end{array}$

Subscripts

f fluidum

s solids

w wall

o without solids

\section{Superscripts}

o superficial

* determined with data from the optical measuring system

\section{Acknowledgements}

The authors greatly acknowledgc U. Cakici and M. Jonker for their assistance in conducting the experiments, and G. Schorfhaar for his accurate technical support.

\section{References}

[1] J.W. van Breugel, J.J.M. Stein and R.J. de Vries. Proc. Inst. Mech Eng. London, Parr 3, IR4 (1969) p. 18.

[2] H. Weinstein, R.A. Graff, M. Meller and M.J. Shao, in D. Kunii and R. Toei (eds.), Proc. 4th Inr. Conf. Flaidizatiom. Enginesting Foundalion, New York, 1983, pp. 299-306.

[3] H. Weinsiein, M.H. Shao and M.G. Schnitzlitin, in P. Basu (ed.), Proc Ist Int. Conf. Circulating Flaidized Bed Technology. Pergamon, 1986. pp. 201-206.

[4] R.J. Dry, Powder Technol., 49 (1986) 37

[5] H. Takeuchi, T. Hisaba, T, Chiba, J. Biswas and L.S. Leung, Powder Technol, 47 (1986) 195

[6] E.-U. Hartge, Y. Li and J. Werther, in P. Basu (ed.), Proc. Ist Imt Couf. Circulating Fluidized Bed Technolugy, Pergamon, 1986. pp. $153-160$.

[7] E.-U. Hartge, Y. Li and J. Wenher, in K. Øslergaard and A. Sørensen (eds.), Proc. 5th Int. Conf. Fluidization, Engineering Foundalion, New York, 19B6, pp. 345-352.

[8] L. Monceaux, M. Azzi, Y. Molodtsof and J.F. Large, in P. Basu (ed,), Proc, Ist Int. Conf. Circulating Fluidized Bed Techmology. Pergamon, 1986. pp. 185-191.

[9] R. Bader, J. Findlay and T. Knowlton, in P. Basu and J.F. Large (eds.) Pruc. 2nd Int, Conf. Circulating Fluidized Ded Tecimology. Pergamon. Oxford. 1988, pp. 123-138.

(10) M.G. Schnitztein and H. Weinstein, in P. Basu and J.F. Large (eds.). Proc. 2nd Int. Conf. Circuluting Fluidized Bed Technology, Pergamon, Oxford. 1988, pp. 205-212.

[11] K. Kato, T. Takarada, T. Tauura and K. Nishino, in B. Busu, M. Horio and M. Hasatani (eds.). Proc. 3rd Int. Conf. Circulating Fluidized Bed Technology, Pergamon, Oxford, 1991, pp. 145-150.

[12] U. Arena, A. Cammarola and L. Pistone, in P. Basu (ed.), Proc. I.xt Int. Conf. Circulating Fluidized Bed Techunlogy, Purgamon, 1986, pp. 119-126.

[13] U. A rena, A. Cammarota, L, Massimilia and D. Pirozzi, in P. Basu and J.F. Large (wds.), Pruc: 2nd Im. Conf. Circulating Fluidized Bed Technology, Pergaman, Oxford, 1988, pp. 223-230.
[14] A.G.J. van der Ham, Ph.D. Disseriation, Twente Unjversity, The Necheriands, 1994.

[15] M.P. Martin, P. Turlier, J.R. Bernard and G. Wild, Powder Tecimol., 70 (1992) 249

[16] W. Zhang. Y. Tung and F. Johnsson, 1991, Chem. Eng. Sci.. 46 (1991) 3045.

[ 17] B. Herb. S. Dou, K. Tuzla and J.C. Chen, AlChE Symp. Ser., 87 ( 1991 ) 299.

[18] D.R. Bai, Y. Jin, Z.Q. Yu and J.X. Zhu, Powder Tecimol., 7 ( 1992) 51.

[19] M. Ishida, T. Shirai and A. Nishiwaki, Powder Technol., 27 (1980) I.

[20] M. Ishida and H. Halano, in D. Kunii and R. Toei (eds.), Proc, 4th Int. Conf. Fluidization, Engineering Foundation. New York, 1983, pp. 61-68.

121) B. Palrose and H.S. Caram, A/ChE J., 28 (1982) 604.

[22] M. Kamiwano and F. Saito, AlChE Symp. Ser., 80 (1984) 122.

[23] S.C. Saxena and D.C. Palel, AlChE Symp. Ser. 84 (1988) 36.

[24] E.-U Hartge, D. Rensner and J. Wenther, in P. Basu and J.F. Large (eds.), Proc. 2nd ht. Conf. Circulating Fluidized Bed Tecimology, Pergamon, Oxford, 1988, pp. 165-180.

[25] E.-U. Hartge, Ph.D. Disserfation, Technische Universität HamburgHarburg, Harnburg-Harburg, Germany, 1989.

[26] E.-U. Hartge, D. Rensner and J. Werther, Chem. Ing. Tech, 9 ( 1989) 744.

[27] T. Dyaskowski and R.A. Williams, Powder Technol., 77 (1993) 135.

[28] Y. Matsuni, H. Yamaguchi, T. Oka, H. Kage and K. Higashitani, Powder Technol., 36 (1983) 215.

[29] M. Horio. K. Morishita, O. Tachibana and N. Murata, in P. Basu and J.T. Large (eds.), Pris. 2nd Im. Comf. Circulating Fluidized Bed Technology, Pergamon, Ox ford, 1988, pp. 147-154.

[30] H. Ishii, T. Nakajima and M. Horio, J. Chem. Eng. Jpm., 22 (1989) 484.

[31] M. Tsukada, D. Nakanishi and M. Horio, in A.A. Avidan (ed.). Proc. frh Int. Conf. Circulating Fluidized Beds, Hidden Valley. Somerset. PA, USA, 1994, pp. 209-215.

[32] G. Qian and J. Li, in A.A. Avidan (ted.). Proc. th tht. Comf. Circulating Fluidized Beds. Hidden Vulley, Somerset. PA. USA. 1994, pp. 274-278.

[33] L. Reh and J. Li, in P. Basu, M. Horio and M. Hasakani (eds.), Proc. 3rd Int Conft Circulating Flitdized Bed Technology. Pergamon. Oxford, 1991, pp. 163-170.

[34] M. Yianneskis. Powder Techunl. \$9 (1987) 26 ].

[35] Y. Tsuji, Y. Morikawa and H. Shiomi, J, Fuid Mech., 139 \{1984] 417.

|36| Y.L. Yang, Y. Jin, Z.Q. Yu, Z.W. Wang and D. Hai, in P. Basu, M. Horio and M. Hasatani (eds.). Proc. 3rd Inr. Conf. Circulating Flaidized Bed Technelogy, Pergamon, Oxford, 1991, pp. 201-206.

[37] Y. Levy and F.C. Lockwood, AlChE J., 29 (1983) 889.

[38] Y.L. Yang. Y. Jin, Z.Q. Yu and Z.W. Wang. Powder Technol., 73 (1992) 67.

[39] T. Wang, Z.J. Lin, C.M. Zhu, D.C. Liu and S.C. Saxena, AJChE J., 39 (1993) 1406.

[40] B.S. Brewster and J.D. Seader. A/ChE J., 26 (1980) 325.

[41] T. Kojima, K.l. Ishihara, Y. Guilin and T. Furusawa, J. Chem. Eng. Jpn., 22 (1989) 341.

[42 I S. Morouka, K. Kusakabe. N. Ohnishi. F. Gujima and H. Malsuyama, Powder Technol., $58(1980,271$.

[43] F. Hamdullahpur. M.J. Pegg and G.D.M. MacKay, Int. J. Mutiphase Flow., 13 (1987) 379.

[44] U. Mann and E.J. Crosby, Ind. Ens. Chem. Proc., 16 (1977) 9.

[45] G. Raso, G. Tirabasso and G. Donsi, Powder Tethnol., 34 (1983) 151 ,

[46] S.L. Soo, G.J. Trezek, R.C. Dimick and G.F. Hohnstreiter, Ind. Eng. Chem. Fundom., 3 (1964) 98.

[47] G.E. Klinzing. A. Zaltash and C. Myler, Part. Sci. Techisl., 5 ( 1987) 95. 
[48] J.B. Gajewski and W. Kala, Proc, th the. Conf. Electrostatics, ELSTAT, 1990, Materials Science XVI, pp. 113-120.

[49] J.B. Gajewski, B. Glód and W. Kala, Inst. Phys. Conf. Ser., //8 (1991) 159

[50] 1.B. Gajewski, B. Glód and W. Kala, IEEE Trans. Ind. Appl., 29 (1993) 650.

[51] B. Herb, K. Tuzla and J.C. Chen, in J.R. Grace, L.W. Shemilt and M.A. Bergougnou (cds.), Prac. 6th Int. Comy. Fluidization. Engineering Foundation, New York, 1989, pp. 65-72.

[52] C.A. Riley and M. Louge, Fur. Sci. Techrol., 7 (1989) 51

[53] M. Louge, D.J. Lischer and H. Chang. Powder Technol., 62 (1990) 269.

[54] L.J. Gajdos and T.W. Bierl, DOE-Repor1 FE-24\$9-8, 1978.

[55] M.J. Rhodes, Powder Technol., 60 (1990) 27.

[56] B.J. Harris, J.F. Davidson and Y. Xue, in A.A. Avidan (ed.). Proc thi Int. Conf. Circulating Fluidized Beds, Hidden Valley. Somerset. $P A$, USA, 1994, pp. 103-110.
[57] B. Herb, S. Dou, K. Tuzia und J.C. Chen, Powder Technol, 70 (1992) 197.

[58] A. Miller and D. Gidaspow, A/ChE J., 38 (1992) 1801.

[59] J.S. Lin, M.M. Chen and B.T. Chao, A/ChE J., 31 (1985) 465.

[60] P.1. Viitanen. Ind. Eng. Chem. Res., 32 (1993) 577.

[61] R.N. Bartholomew and R.M. Casagrande, ind. Eng. Chem., 49 ( 1957) 428.

[62] A. Berker and T.J. Tulig, Chem. Eng. Sci., 4 (1986) 821

[63] M. Azzi, P. Turlier, J.R. Bernard and L. Garnero. Powder Technol. 67 (1991) 27.

[64] E.W. Grohse, AIChE J., I (1955) 358.

[65] S.H. Sheen and A.C. Raptis, Part. Sci. Technol., 5 (1987) 219.

[66] W.H. Press, Numericul Recipes in Pascal: The Ant of Scientific Computing. Cambridge University Press, UK, 1990.

[66] W.H. Press. Numerical Recipes in Pascal: The Ant of Scientijic Computing. Cambridge University Press, UK, 1990. 